\title{
Investigation of the Stress-Strain State of a Wheel Flange of the Locomotive by the Method of Finite Element Modeling
}

\author{
Kenes ZHUSSUPOV*, Aliya TOKTAMYSSOVA**, Seidulla ABDULLAYEV***, \\ Gabit BAKYT****, Manarbek YESSENGALIYEV*****, Madina BAZARBEKOVA****** \\ *Department of Automobiles, Road Machinery and Standardization, Kazakh Academy of Transport and Communications \\ named after M. Tynyshpayev, Shevchenko Str., 97, Almaty 050012, Kazakhstan,_E-mail: kenes_atabai@mail.ru \\ **Department of Transport Logistics, Department of Automobiles, Road Machinery and Standardization, Kazakh Academy \\ of Transport and Communications named after M. Tynyshpayev, Shevchenko Str., 97, Almaty 050012, Kazakhstan, \\ E-mail: aliya_311@mail.ru \\ ***Rolling Stock Department, Kazakh Academy of Transport and Communications named after M. Tynyshpayev, \\ Shevchenko Str., 97, Almaty 050012, Kazakhstan, Corresponding author: E-mail: seidulla@mail.ru \\ E-mail: seidulla@mail.ru \\ ****Rolling Stock Department, Kazakh Academy of Transport and Communications named after M. Tynyshpayev, \\ Shevchenko Str., 97, Almaty050012, Kazakhstan,_E-mail: gaba_b@bk.ru \\ *****Department of Automobiles, Road Machinery and Standardization, Kazakh Academy of Transport and Communica- \\ tions named after M. Tynyshpayev, Shevchenko Str., 97, Almaty 050012, Kazakhstan, E-mail: m.esengaliev@mail.ru

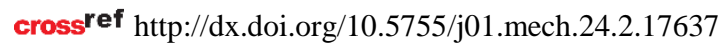

\section{Introduction}

The wheel bench is one of the most critical elements of the locomotive, since their condition directly affects the safety of locomotive [1-3]. Wheelset transferring the load from the weight of the locomotive on the rails that guide the movement of the locomotive along the rail track and with the application of torques from the engines ensure the realization of traction force [4-6]. In addition to these loads, wheelsets perceive additional dynamic forces associated with the vibrations of the locomotive and the bumps when driving on the track with irregularities, and the presence of irregularities on the surface of the wheels; the braking Shoe working surface of the wheel engages with the brake shoe.

Dynamic forces of interaction between wheels and rails is significantly dependent on undersprung mass of the locomotive, most of which were mass wheelset. To reduce these forces, it is advisable to reduce the weight of the wheelset [7-9].

The forces of interaction of wheels and rails, providing a direction of movement of the locomotive is dependent upon the configuration of the profile of the tire, which should be chosen to ensure the driving safety and the conditions of stability from the wheels' derailment [10-12].

Mutual slippage of the wheels associated with the difference in their diameters, reduce the thrust force $[1,13$, 14]. It is therefore advisable to choose a wheel profile to wears the tread surface in the process of exploitation was minimal.

With the aim of reducing the wear rate of the contact spots to acceptable values held a series of technical and organizational nature: lubricate, better design of road and rolling stock, improvement of the profile geometry of the surface of the $\mathrm{CP}$ and the rails. However, these measures do not solve adequately the problem.

Thus, the purpose of this article is to analyze the negative aspects of the interaction of wheel and rail, which lead to intensive wear of the wheel flange.

\section{Methods}

In the Republic of Kazakhstan, the locomotives of the series TE33A (production on technology of the USA) were put into operation. Currently operated a fleet of locomotives is:

- electric locomotives VL80C - 368 units;

- the locomotives of the series TE33A - 285 units.

Locomotive VL80C-mainline electric freight locomotive, AC, was built by Novocherkassk electric locomotive plant (NELP) project developed VEIRI in the period from 1961 to 1995.

Locomotive TE33A (Evolution ES44ACi) is a freight locomotive with asynchronous traction drive developed by GeneralElectric company (USA) and manufactured by locomotive plant "locomotive KurastyruZauyty" in Astana.

During the dynamic and travel testing, and other technical documentation, the basic settings of locomotives are distinguished needed for the calculation of the path of strength. The estimated parameters are given in Table 1 [15].

Increased wear of the ridges wheelset mainline freight locomotive TE33A necessitated the determination of the optimal ways to reduce the intensive wear of the ridge. To accomplish the purpose of the work was used the program complex finite-element mechanical-mathematical modeling "ANSYS". This program allows to calculate the stress-strain state of the contact zone of wheel and rail.

The value of static and dynamic contact stresses effect on the wear of the surfaces of interaction of rails and wheels, the friction coefficient between them and represents the type of the deformation. The contact stress is affected by:

- level static load on the wheel and its diameter;

- the state of the profiles of wheel and rail;

- the spectral composition of the short continuous roughness on rails and wheels;

- parameters of the chassis and the traction drive rolling stock and track; 
- mode and speed in both straight and curve track sections.

The estimated parameters of locomotives

\begin{tabular}{|l|c|c|}
\hline \multicolumn{1}{|c|}{ Parameter } & \multicolumn{2}{c|}{ Locomotive } \\
\cline { 2 - 3 } & VL80C & TE33A \\
\hline Axial characteristics & $2\left(2_{0}-20\right)$ & $\mathrm{C}_{0}-\mathrm{C}_{0}$ \\
\hline Design speed, km/h & 110 & 120 \\
\hline Static load from the wheel on the rail, $\mathrm{kN}$ & 235 & 113 \\
\hline Wheel diameter, $\mathrm{m}$ & 1,25 & 1,05 \\
\hline Public static deflection, mm & 71,8 & 145,5 \\
\hline Weight neobressorennyh parts of the crew assigned to 1 wheel, $\mathrm{kN}$ & 27 & 37,9 \\
\hline Wheelbase (in $\mathrm{m})$ & 4,8 & $1,85-1,85$ \\
\hline
\end{tabular}

Quantitative evaluation was performed for the new profile rail type R65 and wheels of the locomotive TE33A profile Dmeti thickness of the ridge from 23 to $27 \mathrm{~mm}$. in addition, for comparison, also the calculated profiles "Research and Design Technological Institute of Rolling Stock" (hereinafter RDTIRS) and new wheel electric locomotive VL80C. Model of wheel and rail was created according to the GOST in the software complex three-dimensional simulation "SolidWorks" in Fig. 1.

A three dimensional model of wheel and rail created in "SolidWorks" in the further, were imported into the software "ANSYS" (Fig. 2).

These models were subsequently split into scaled elements (Fig. 3), where, as it approaches the zone of interaction between wheel-rail, a finite element mesh is condensed, thus to reduce the error in the calculation of contact

stresses, the sizes of the elements in the contact zone up to $1 \mathrm{~mm}$.

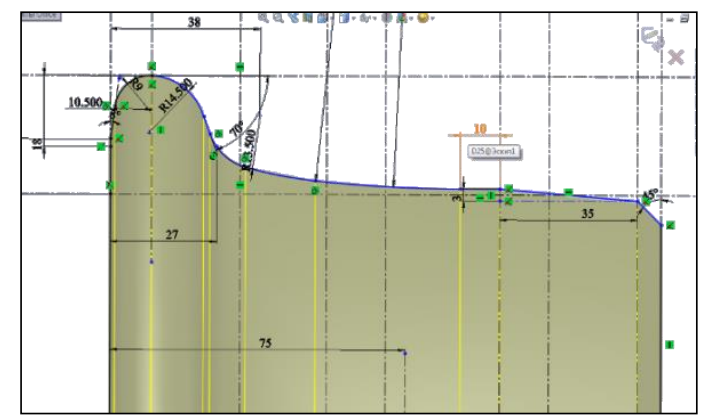

Fig. 1 Wheel Profile of the locomotive TE33A thick flange $27 \mathrm{~mm}$

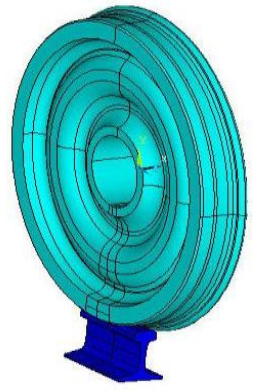

a

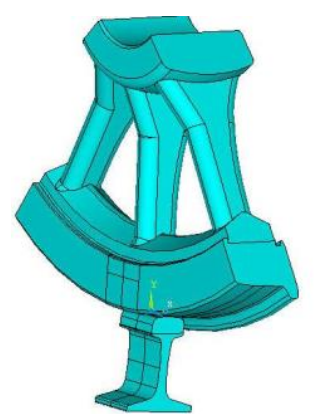

b

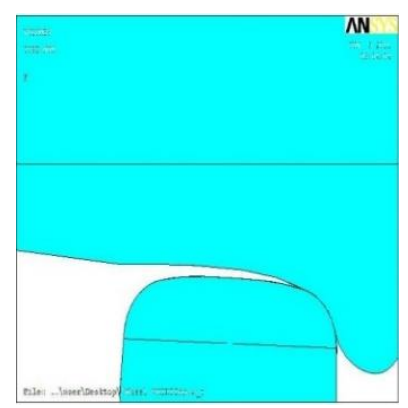

c

Fig. 2 Three-dimensional model of wheel and rail: a - TE33A, b - VL80, c-RDTIRS

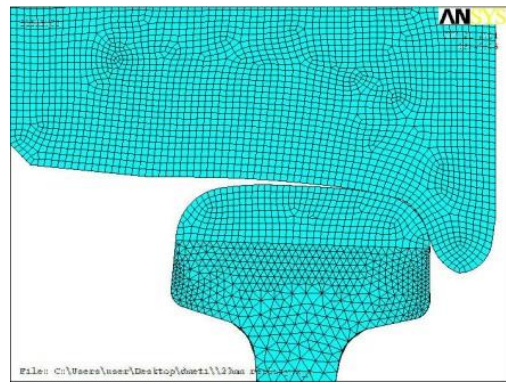

a

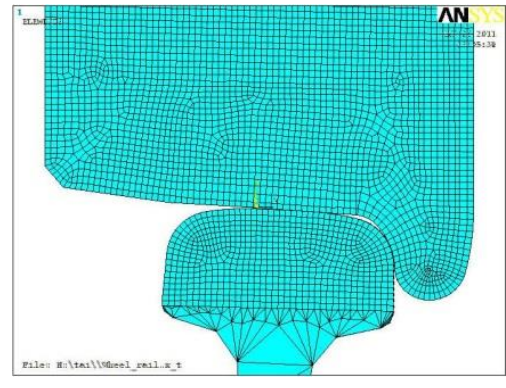

b

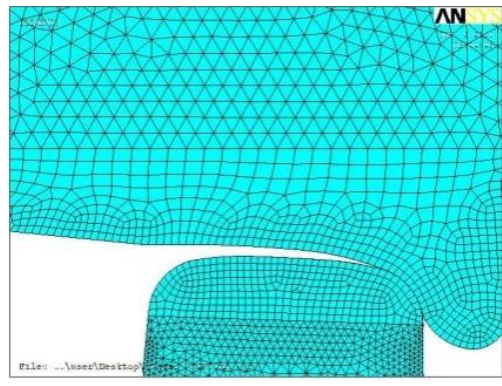

c

Fig. 3 Three-dimensional finite element model of wheel and rail: a - TE33A, b - VL80, c - RDTIRS

For the solution of the contact problem in the software "ANSYS" there are a number of contact elements, which may be formed the contact surfaces: "surface-to-surface, node-to-surface and node-to-node". To quantify the stress-strain state (hereinafter, SSS) in the contact zone of the contact surface was formed using the contact elements of the "surface-surface".

Contact elements use a "target surface" and "surface contact". The target surface for three-dimensional models is modeled with TARGE170, the contact surface is modeled by elements CONTA173, CONTA174 (Fig. 4). 


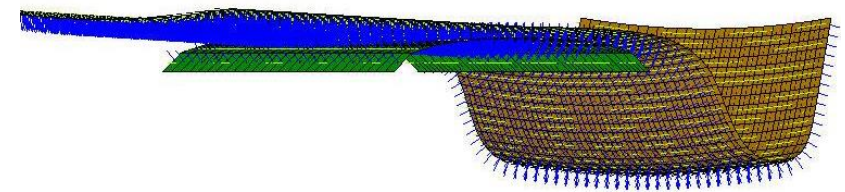

Fig. 4 The model of the contact "wheel-rail" surface that the authors created

These contact elements, in comparison with other contact elements that allow us to calculate the nonlinear contact problem in the presence of large deformations in contact and sliding friction, to carry out a more accurate calculation of normal and tangential stresses, and have no restrictions on the shape of the target surface.

\section{Data, analysis and results}

Norms of permissible speeds are established based on indicators of dynamics, strength of metal structures, the impact on the path of outstanding acceleration in curves, stability against derailment of the wheels with the rails.

The permissible speed in curves of different radii and can't under the terms of outstanding not to exceed the permissible acceleration is determined by the formula:

$$
V=\sqrt{13 R\left(a_{u a}+\frac{h g}{S_{1}}\right)}
$$

where: $V$ is the speed of the carriage, $\mathrm{km} / \mathrm{h} ; S_{1}$ is the distance between the axes of rails for track with width of $1520 \mathrm{~mm}$, $S_{1}=1600 \mathrm{~mm} ; g$ is the acceleration of gravity, $g=9,81 \mathrm{~m} / \mathrm{s}^{2}$; $R$ is the radius of the curve, $\mathrm{m} ; h$ is vertical setting of rail, $\mathrm{mm}$.; $a_{u a}$ is horizontal unbalanced acceleration, $a_{u a}=0,7 \mathrm{~m} / \mathrm{s}^{2}$.

Table 2 shows the limits of speed for locomotives of the series KZ4AC, KZ8A, TE33A for typical path construction [15].

Table 2

Permissible speed of the locomotives series KZ4AC, KZ8A, TE33A for typical path construction

\begin{tabular}{|c|c|c|c|c|c|c|c|c|c|}
\hline \multirow{3}{*}{ Series of locomotive } & \multicolumn{8}{|c|}{ The permissible speed, $\mathrm{km} / \mathrm{h}$} \\
\cline { 2 - 11 } & \multirow{2}{*}{ Straight line curve radius, $\mathrm{m}$} \\
\cline { 3 - 11 } & & 1000 & 800 & 700 & 600 & 500 & 400 & 350 & 300 \\
\hline VL80C & 110 & 110 & 110 & 110 & 100 & 95 & 85 & 75 & 70 \\
\hline TE33A & 120 & 120 & 120 & 120 & 115 & 105 & 95 & 85 & 80 \\
\hline
\end{tabular}

The calculation of nonlinear contact problems was carried out by iteration method of Newton-Raphson, involving an approximate split load on several successive increments and convergence of the nonlinear problem to a linear one. Thus, the accuracy of the solution is determined by the number of increments and time steps and equilibrium iterations. The boundary conditions for wheel and rail was asked in the following order: soles and at the ends of the rail were not allowed to move in all three directions of Cartesian coordinates, the vertical wheel load was set in the center of the hub equal to $120 \mathrm{kN}$, a lateral force on the wheel flange is
$90 \mathrm{kN}$, which corresponds to the passage of the locomotive curve of radius $290 \mathrm{~m}$, the can't $54 \mathrm{~mm}$, at a speed of 70 $\mathrm{km} / \mathrm{h}$.

Mechanical properties of materials for the wheel and rail are presented in Table 3, which shows that the yield strength of metals for rail is lower than the wheels.

The curve of the nonlinear plastic deformation of materials of the wheels and rails of the voltage presented in Fig. 5. As can be seen from the figure, the yield strength for the wheel material occurs at $650 \mathrm{MPa}$, the volumetric tempered rails $460 \mathrm{MPa}$.

Table 3

The mechanical properties of the materials of wheel and rail

\begin{tabular}{|c|c|c|c|c|}
\hline Element & Young's modulus, $E, P_{a}$ & Poisson ratio, $v$ & Density $\rho, \mathrm{kg} / \mathrm{m}^{3}$ & Conventional yield strength $\sigma t, \mathrm{MPa}$ \\
\hline Rail P65 & $2,1 \cdot 10^{11}$ & 0,3 & 7850 & 460 \\
\hline Wheel & $2,1 \cdot 10^{11}$ & 0,3 & 7850 & 650 \\
\hline
\end{tabular}

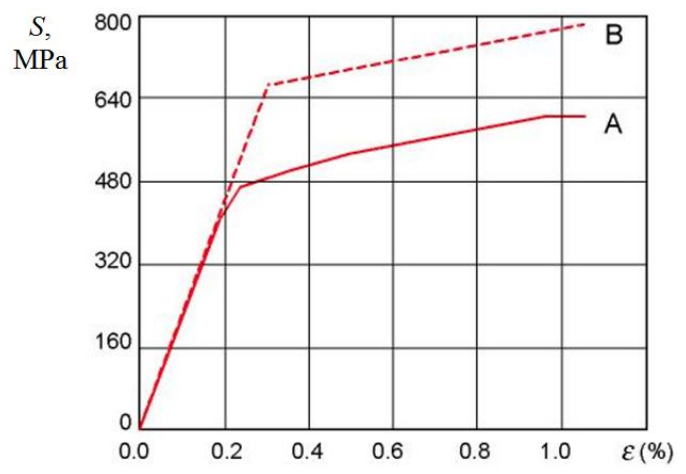

Fig. 5 Nonlinear dependence of elastic-plastic stress-strain of A-rail, B-wheel: $\varepsilon(\%)$ - deformation of the metals of the wheel and rail, $S(\mathrm{MPa})$ - stress-strain state of the metal wheel and rail in the area of their mutual contact
It is known that the materials of wheel and rail in terms of three-dimensional stress state near the center of the elliptic contact area are experiencing the full compression which they can withstand a fairly high voltage. According to the strength theory of Mor in the volumetric stress state of the contacting materials dangerous are not the greatest normal stress in the considered point, and the highest shear stresses in them, equal to half-difference between the largest and smallest principal stresses.

With the increase of the friction forces $(f=0,3)$, with the passage of the locomotive of the curve in the contact zone of the wheel flange to the inner edge of rail head, combined with the normal forces, tangential forces occur, which change the stress distribution on the surface (Fig. 6).

Subsurface stress Mises-Hencky inside and close to the contour of the contact pad presented in Fig. 7. 


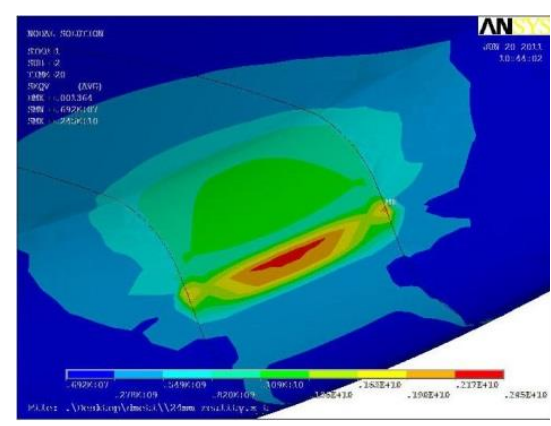

a

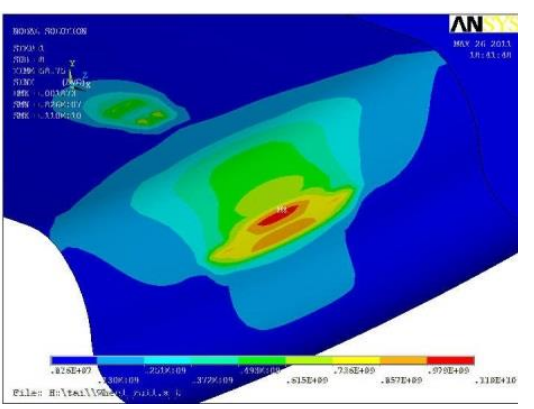

b

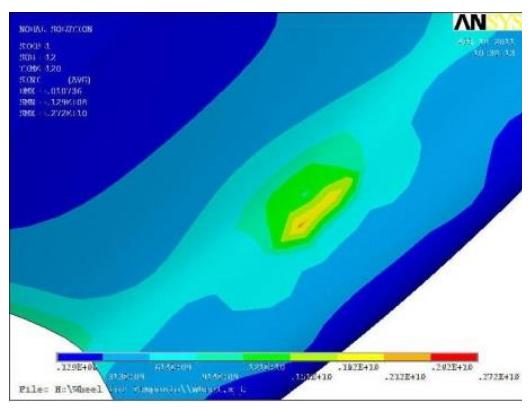

c

Fig. 6 Voltage on the condition of Mises-Hencky on the working surface of the flange: a - Dmeti, b -the new wheel VL80, c-RDTIRS

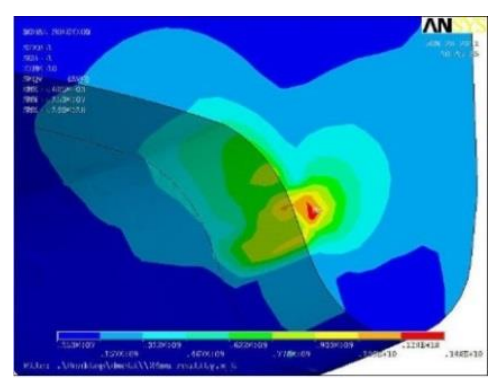

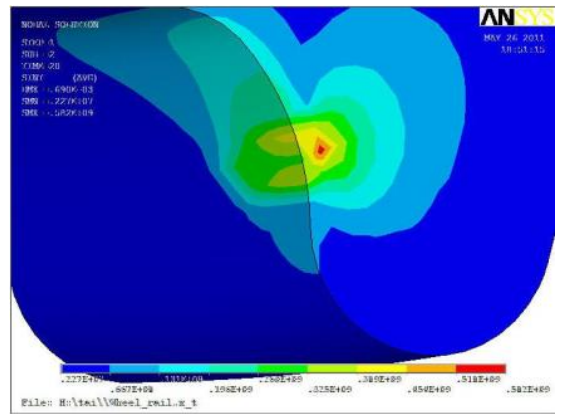

b

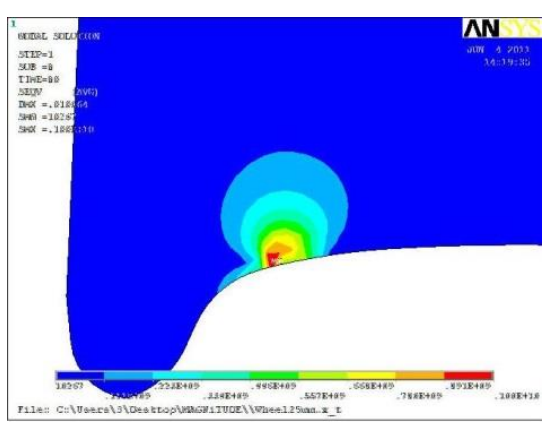

C

Fig. 7 Subsurface stresses for the condition of Mises-Hencky: a - Dmeti, $b$-the new wheel VL80, c - RDTIRS

As can be seen from Figs. 6 and 7, the most intense are the Dmeti profiles with two-point contact. The red zone of the wheel flange corresponds to tensile stresses. This flow is mainly two processes of destruction: the volumetric plastic deformation (crushing) and abrasion. Volumetric plastic deformation is uniform along the depth from the surface, reaches the highest values near the surface and decreases as the distance from it. According to [16], the pressure in the contact "wheel-rail" in real operating conditions varies from $1.7 \tau$ ( $\tau$ is the yield strength of wheel and rail steel) to $3 \tau$ and more. The result of plastic deformation is metal flow from the area of the base of the ridge at the surface and at the top of the crest. At the same time changing the location and magnitude of maximum shear stresses, and the ratio between the surface and deep contact stress. On the surface of the contact tangential force (Figs. 8-9) increase tensile stresses on the front (counting in the direction of the forces) part of the contour of the contact area and reduce strain on the back.

In the calculation of the finite element evaluation of the stress state, we performed the maximum normal stress $\sigma_{z \max }$ and the condition of plasticity Mises-Hencky [3] according to the expression:

$$
\frac{1}{\sqrt{2}} \sqrt{\left(\sigma_{1}-\sigma_{2}\right)^{2}+\left(\sigma_{2}-\sigma_{3}\right)^{2}+\left(\sigma_{3}-\sigma_{1}\right)^{2}}=\sigma_{T}
$$

Based on the calculation results it was found that the maximum equivalent stress von Mises-hencky for all variants of calculation exceed the yield strength of the material of the wheel and rail. For clarity, the calculation results for the stress-strain state are summarized in table 4 and a graph is constructed (Fig. 10).

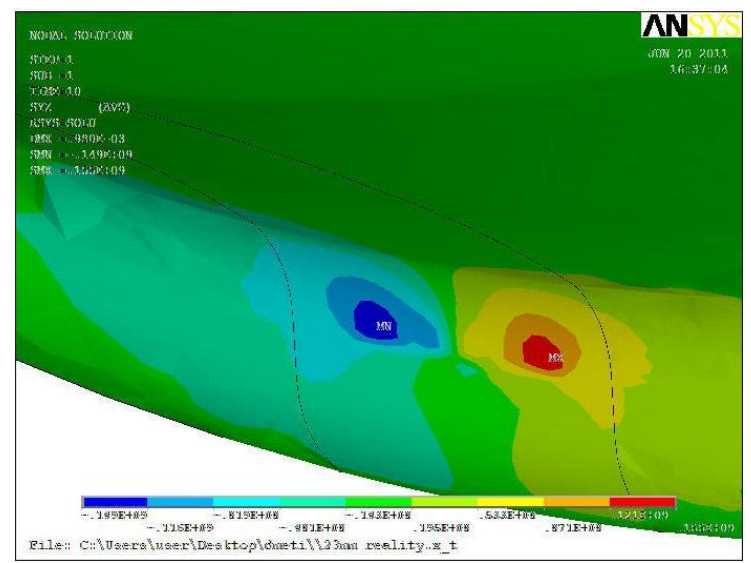

Fig. 8 Shear stresses arising from sliding the flange on the inner edge of rail head

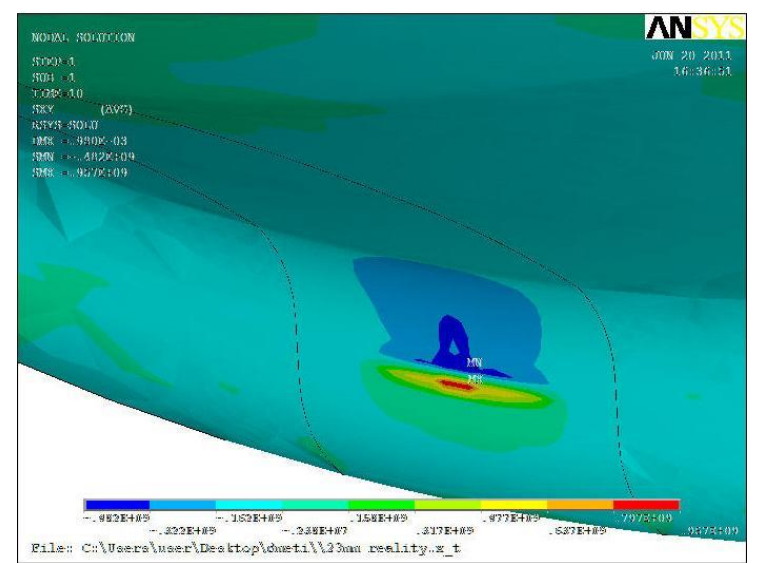

Fig. 9 Shear stresses occur when the creeping of the flange on the head of the rail 
The calculation results also found that the von Mises-hencky for the wheels of an electric locomotive VL80 turns almost at the same level with the wheels TE33A.

Table 4

The results of calculation of stress-strain state of wheels

\begin{tabular}{|l|c|c|c|c|c|c|c|}
\hline & \multicolumn{7}{|c|}{ Name } \\
\hline The type of rail & \multicolumn{5}{|c|}{ The thickness of the flange TE33A } & \multirow{2}{*}{$\begin{array}{c}\text { Profile } \\
\text { RDTIRS }\end{array}$} & Profile GOST \\
\cline { 2 - 9 } & $23 \mathrm{~mm}$ & $24 \mathrm{~mm}$ & $25 \mathrm{~mm}$ & $26 \mathrm{~mm}$ & $27 \mathrm{~mm}$ & 1100 & 1500 \\
\hline The type of wheel & 1930 & 1400 & 1500 & 1650 & 1690 & 100 \\
\hline
\end{tabular}

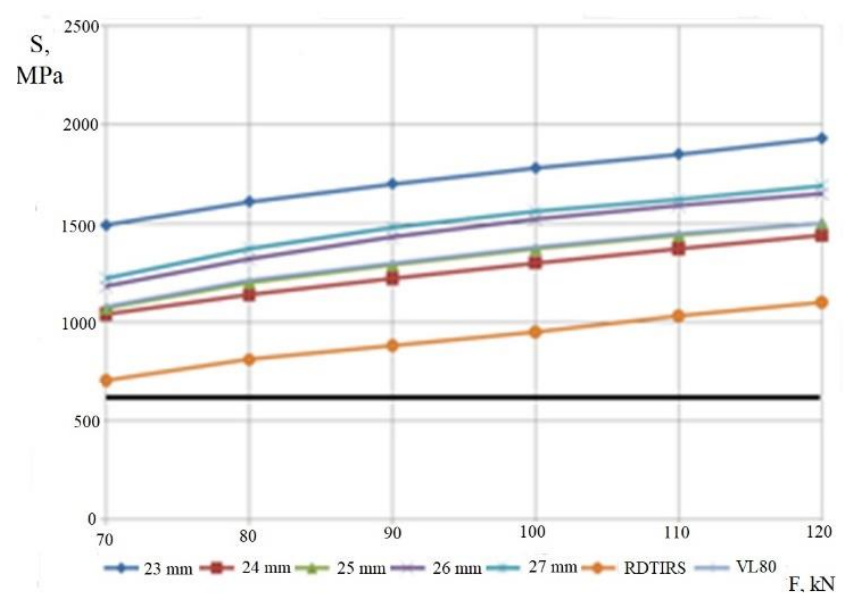

- the yield strength of the metal of the wheel

Fig. 10 The dependence of flange SSS of wheels on the load

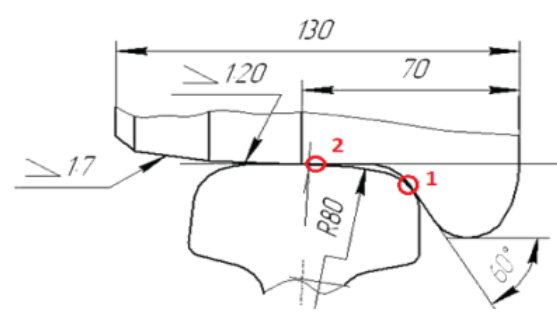

a
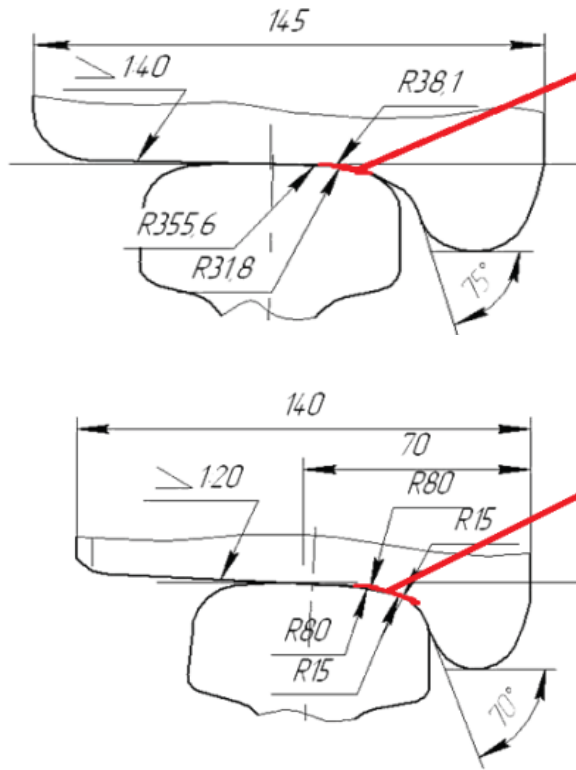

b
As the graph shows, the maximum value of voltage plasticity wheels TE33A with a thickness of $23 \mathrm{~mm}$ flange exceed the limit of proportionality in three times, and then the flow of metal from the area of the base of the ridge at the surface and at the top of the crest, resulting in intensive abrasion of the working surface of the flange.

It is also worth noting that throughout the range of the thickness of the ridges for the wheels TE33A voltage plasticity turn out significant.

The most favorable form stress plasticity profile, RDTIRS - $1100 \mathrm{MPa}$. Contours of the stress-strain state on the condition of Mises-Hencky wheel flange is illustrated in figures 6-7. Increased wear of the wheel flange of the locomotive, as shown by the results of calculations and numerous studies and foreign experience, is a two-point contact of wheel and rail (Fig. 11). This is, primarily, due to the small contact area of the wheel flange to the inner edge of the rail, the size of which are much smaller than the area of the contact surfaces of rail and rolling wheel at the same pressure.

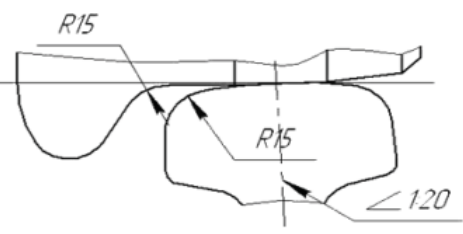

conformal contact

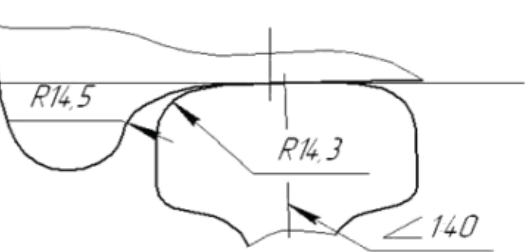

conformal contact

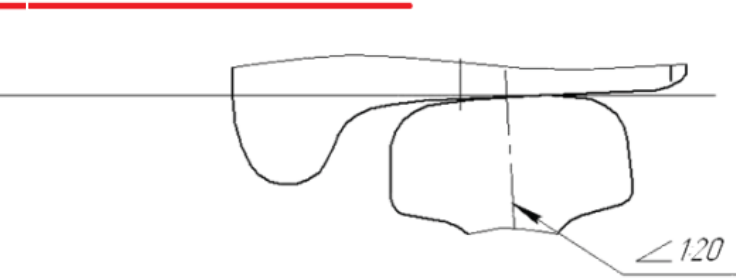

c

Fig. 11 Position of wheel pair in a track: a - the profile of the wheel GOST 9036-88, rails R65 GOST p51685-2000 (Russia), $\mathrm{b}$ - the profile of the wheel AAR-1B, rail FREA 136RE (USA), c - the proposed profile of wheels, rails R65 
In Fig. 11, b) and c) show the conformal profiles of wheels and rails, which have a greater area of contact between the wheel and the rail.

\section{Discussion}

For example, considering the original two-point contact in the system "wheel-rail" (Kazakhstan) and used in

Speed $45 \mathrm{~km} / \mathrm{h}$

Striker angle of $0.012 \mathrm{rad}$

Curve radius $300 \mathrm{~m}$

The elevation of the rail $90 \mathrm{~mm}$

1. Russia

The wheel GOST 9036-88

(957 MM)

GOST P51685-200

Canting of rails $1 / 20$

\section{USA}

Wheel of US standard

S-669 (1067 mm)

Rail 136 RE

Canting of rails $1 / 40$

1. Russia

The wheel GOST 9036-88 (957)

of profile, RDTIRS

Rails R65

GOST P51685-200

Canting of rails $1 / 20$

Wear factor

$F_{\text {wear }}=k \bullet V c k \bullet \sigma$ the United States conformal contact of the wheel and rail, see the following: to operate a mutual contact surface for conformal profiles USA a more stable geometry, the breakin period is faster, the load is distributed over a greater area of contact, there are no regions with a higher specific pressure and high sliding velocities (Fig. 12), and wear life is increased.
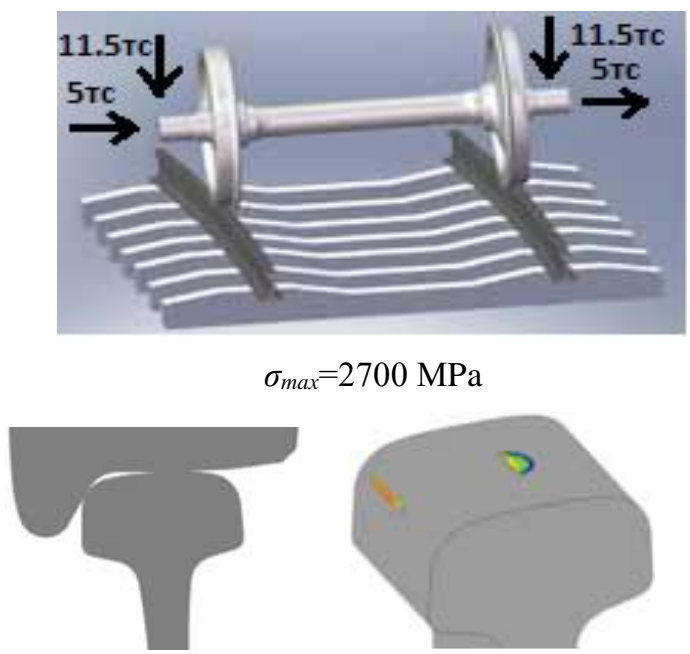

$\sigma_{\max }=2100 \mathrm{MPa}$
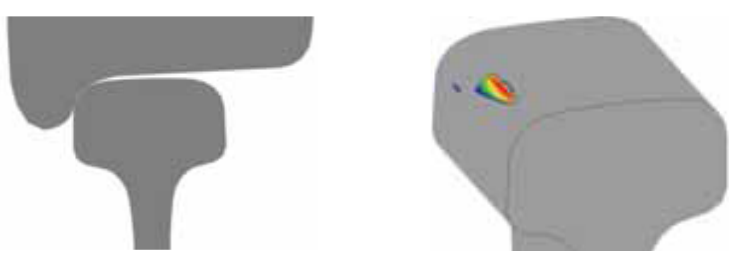

$\sigma_{\max }=2250 \mathrm{MPa}$
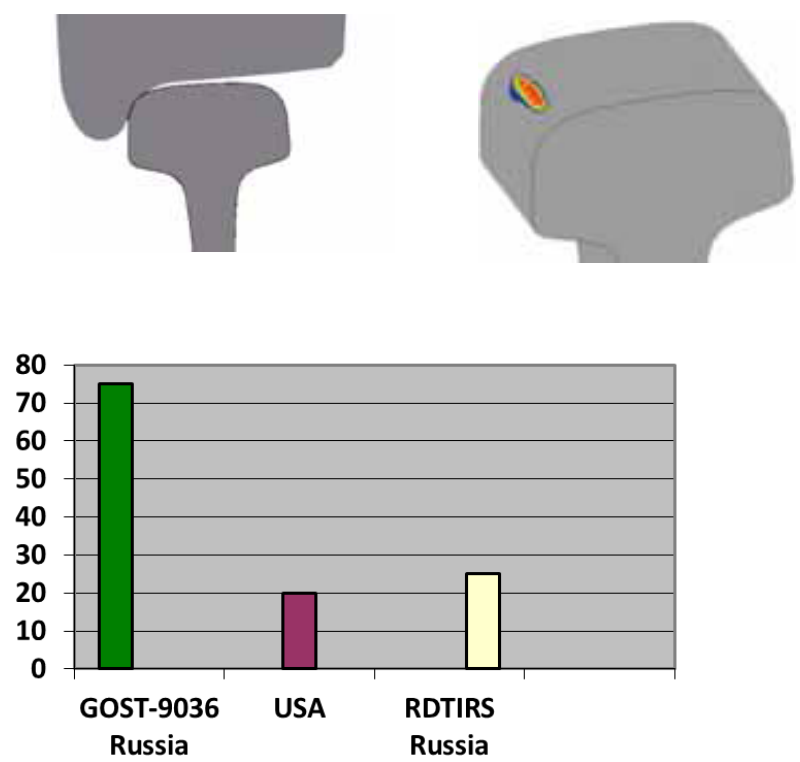

Fig. 12 Effect profiles of the contact wheel-rail on the factor of wear and tear: translation of elements: $m c-$ ton-force

On the basis of the calculation rationale for the use of solid-rolled wheels with the ridge thickness of $23 \mathrm{~mm}$, it is possible to draw the following conclusions:

- domestic profiles Dmeti are at increased, it is primarily associated with stresses exceeding the yield strength of the material of the wheel is 3 times that arise in the working area of the ridge during the passage of the locomotive curve.

- during plastic deformation begins to occur, the processes of abrasion, which includes: a microslice, gripe, fatigue crack formation which can lead to fracture of the ridge. 
Contact fatigue and wear are the competing mechanisms of damage and when combined with certain conditions alternately occur on the Railways, leading to high turnover of wheels and rails [4].

The intensity of wear of the ridges wheelset and lateral wear of rails depends on the loading of the contact zone, velocities relative slippage of the wheel determined by the angles of nabuhanie wheelset on the rails, temperature in the contact zone, the presence and properties of the third body in the contact zone. From all these parameters the most direct and controllable way is:

- introduction to the contact area of the third body with specified characteristics;

- optimization of wheel profile shape to ensure conformal contact.

Turning the wheel profile will give in the first place:

- reduction of stress and elastoplastic deformation due to the increased area of contact when the movement of the locomotive in the curve;

- reduced speed of slippage of the wheel along the rail.

Therefore, as a first and most quickly implemented measure is lubricate the side surface of the rail head and optimization of the wheel profile.

\section{Conclusions}

1. Installed:

- The wheels of the locomotive turned TE33A profile Dmeti with a thickness of $23 \mathrm{~mm}$ flange to operate are not recommended as they do not meet the requirements of traffic safety of trains.

- For safe operation of the locomotive TE33A maximum allowable size of the thickness of the ridge machined on the profile Dmeti is $24 \mathrm{~mm}$.

The most favorable interaction of wheel and rail voltage plasticity and slip speed for conformal wheel profile, RDTIRS.

2. Offered:

- Apply conformal contact of the wheel and rail, which in turn will improve the dynamic behavior of the wheels in curves and on straight sections of the road will increase the period of time between repairs.

\section{References}

1. Markov D. P. 1995. Increase of hardness of rolling stock wheels (prerequisites and perspectives), Scientific Research Institute of Railway Transport bulletin 3: 1017.

2. Abdullaev S. S.; Bakyt G. B.; Zhaksybergen B. 2011. The study of free vibrations of a diesel electric trains to select parameters for suspension single axle truck, Kazakh Academy of Transport and Communications bulletin, Almaty 6: 6-13.

3. Dudin, M.; Frolova E.; Kuznetsov, M.; Drobysheva, L.; Krasulya, E. 2016. "Green" Logistics as an Instrument for Putting Together a New Model for Professional and Career-Broadening Training in Global Economic Space, International Journal of Environmental and Science Education 11 (15): 8693-8705.

4. Daniel, R. 2015. Effect of malfunctioning of the braking system on thermo-mechanical properties of freight train wheels: dissertation - AAU.
5. Zhang, D.; Hu, H.; Liu, Yu.; Dai, L. 2014. Railway train wheel maintenance model and its application, Transportation Research Record: Journal of the Transportation Research Board 2448: 28-36. https://doi.org/10.3141/2448-04.

6. Jiang, H.; Bian, X.; Cheng, C. 2016. Simulating train moving loads in physical model testing of railway infrastructure and its numerical calibration, Acta Geotechnica 11 (2): 231-242. https://doi.org/10.1007/s11440-014-0327-y.

7. Ienaga, S.; Terumichi, Yo.; Nishimura, K.; Nishina, M. 2016. Numerical and Experimental Study on Contact Force Fluctuation Between Wheel and Rail Considering Rail Flexibility and Track Conditions, Multibody Dynamics, Springer International Publishing, 239-257.

8. Xin, L.; Markine, V. L.; Shevtsov, I. Y. 2016. Numerical analysis of the dynamic interaction between wheel set and turnout crossing using the explicit finite element method, Vehicle System Dynamics 54 (3): 301327. https://doi.org/10.1080/00423114.2015.1136424.

9. Lyu, Y.; Zhu, Y.; Olofsson, U. 2015. Wear between wheel and rail: A pin-on-disc study of environmental conditions and iron oxides, Wear 328: 277-285. https://doi.org/10.1016/j.wear.2015.02.057.

10. Ekberg, A.; Åkesson, B.; Kabo, E. 2014. Wheel/rail rolling contact fatigue-probe, predict, prevent, Wear 314 (1): 2-12. https://doi.org/10.1016/j.wear.2013.12.004.

11. Antolín, P.; Zhang, N.; Goicolea, J. M.; Xia, H.; Astiz, M. A.; Olivera, J. 2013. Consideration of nonlinear wheel-rail contact forces for dynamic vehicle-bridge interaction in high-speed railways, Journal of Sound and Vibration 332 (5): 1231-1251. https://doi.org/10.1016/j.jsv.2012.10.022.

12. Kaewunruen, S. 2014. Monitoring structural deterioration of railway turnout systems via dynamic wheel/rail interaction, Case Studies in Nondestructive Testing and Evaluation 1: 19-24. https://doi.org/10.1016/j.csndt.2014.03.004.

13. Moroz, B. A.; Marutin, K. A.; Balanovsky, A. E.; 1998. A complex system of resource-saving wheels and rails (the experience of the East-Siberian railway), Locomotiv 19: 19-22.

14. Lysiuk, V. S. 2002. The causes and mechanisms of derailment of wheel from rail problem of wear of wheels and rails, Moscow: Transport 215.

15. Abdullayev, S.; Tokmurzina, N.; Bakyt, G. 2016. The determination of admissible speed of KZ4AC, KZ8A, TE33A locomotives on the railway roads of the Republic of Kazakhstan, Poland, Journal of Transport problems 1.

16. Pasholok I. L.; Kharitonov V. B. 1997. On the possible improvement of wear resistance of railway wheels, Scientific Research Institute of Railway Transport bulletin 1: 41-45. 
K. Zhussupov, A. Toktamyssova, S, Abdullayev, G. Bakyt, M. Yessengaliyev

INVESTIGATION OF THE STRESS-STRAIN STATE OF A WHEEL FLANGE OF THE LOCOMOTIVE BY THE METHOD OF FINITE ELEMENT MODELING

S u m m a r y

The rail mode of transport has become the main transit of goods in States with no direct outlets to the world ocean In connection with their health and the necessary technical support key moment in the economic development of the state. In this regard, the paper discusses the negative aspects of the interaction between wheel and rail, leading to intensive wear of the wheel flange on the example operated Kazakhstan electric and diesel locomotives. To achieve this purpose was used the software package "ANSYS". As a result, define the levels of the stress-strain state of a wheel and a rail of finite-element modeling. Developed a methodology for calculating stresses in "the system wheel-rail." Recommendations for maximum permissible thickness of the ridge is machined on the profile Dmeti wheels of the locomotive TE33A. It is also proposed to apply the conformal contact of a wheel and rail that will reduce the risk of wear.

Keywords: conformal contact of the wheel and rail, wear of the flanges of wheelset, deformation of the metals of the wheel and rail, the yield strength of the metal wheel, the dynamic behavior of the wheel.

Received March 08, 2017

Accepted April 18, 2018 